\title{
PAISAGEM LINGUÍSTICA EM CONTEXTO FRONTEIRIÇO: ESTUDO DE CASO EM TABATINGA (BRA) E LETICIA (COL)
}

\author{
LUANA FERREIRA RODRIGUES (UFAM/FAPEAM) ${ }^{1}$
}

\begin{abstract}
RESUMO: Neste artigo, apresento um estudo de caso sobre a paisagem linguística na fronteira entre as cidades de Tabatinga (Brasil) e Leticia (Colômbia), com base nos conceitos de paisagem linguística (BLOMMAERT, 2012; CENOZ; GORTER, 2006), superdiversidade (BLOMMAERT; RAMPTON, 2012; VERTOVEC, 2007) e metrolinguismo (OTSUJI; PENNYCOOK, 2010). Este estudo de caso utiliza, como dados de análise, imagens de placas e letreiros de estabelecimentos comerciais, localizados próximo ao marco de fronteira entre Brasil e Colômbia, fotografadas durante trabalho de campo nas cidades mencionadas; e tem como objetivo pensar a paisagem linguística como um dos instrumentos que podem auxiliar no diagnóstico sociolinguístico dos repertórios comunicativos dos falantes de uma determinada comunidade e o status das línguas nesses territórios fronteiriços. Além disso, proponho pensar a paisagem como um importante recurso para a promoção do multilinguismo e das línguas autóctones invisibilizadas pela hegemonia das línguas oficiais dos países onde se desenvolve o presente estudo. Essa invisibilização é perceptível, conforme aponto no estudo, não apenas na paisagem linguística dessas cidades, mas, também, nos sistemas escolares municipal e estadual ao não se observar a presença dessas línguas nos currículos das escolas regulares, revelando a ausência de uma representação identitária e linguística de grupos étnicos que vivem nesse espaço.
\end{abstract}

PALAVRAS-CHAVE: Paisagem linguística. Fronteira. Superdiversidade. Políticas linguísticas.

ABSTRACT: In this article I present a case study on the linguistic landscape on the border between the cities of Tabatinga (Brazil) and Leticia (Colombia), based on the concepts of linguistic landscape (BLOMMAERT, 2012; CENOZ; GORTER, 2006), superdiversity (BLOMMAERT; RAMPTON, 2012; VERTOVEC, 2007) and metrolinguism (OTSUJI; PENNYCOOK, 2010). This case study uses as data for analysis images of signs and signs of commercial establishments, located near the border between Brazil and Colombia, photographed during field work in the mentioned cities and aims to think of the linguistic landscape as one of the instruments that They can assist in the sociolinguistic diagnosis of the communicative repertoires of speakers of a particular community and the status of languages in these border territories. In addition, I propose to think of landscape as an important resource for the promotion of multilingualism and indigenous languages made invisible by the hegemony of the official languages of the countries where this study is being developed. This invisibility is noticeable, as pointed out in the study, not only in the linguistic landscape of these cities, but also in the municipal and state school system by not observing the presence of these languages in regular school curricula, revealing the absence of an identity and linguistic representation of ethnic groups living in this space.

KEYWORDS: linguistic landscape, border, super diversity, language policies.

\section{INTRODUÇÃO}

São muitos os estudos sobre as fronteiras e suas particularidades em áreas do conhecimento como Geografia, Antropologia, História, Sociologia e Política, por exemplo; mas também têm sido objeto de estudo da Linguística, da Educação e da Política Linguística.

\footnotetext{
${ }^{1}$ Docente do Curso de Letras- Língua e Literatura Espanhola na Faculdade de Letras da Universidade Federal do Amazonas. Doutoranda do Programa de Pós-Graduação em Linguística da Universidade Federal de Santa Catarina e bolsista da Fundação de Amparo à Pesquisa do Estado do Amazonas. Revista Trama | Volume 16 | Número 37 | Ano 2020 | p. 149-160 | e-ISSN 1981-4674
} 


\section{$=$ TRAMA $=$}

Sob o viés da Política Linguística, pesquisadores brasileiros têm desenvolvido estudos sobre o ensino de línguas e as políticas para as línguas em contexto de fronteira, cuja maioria dos trabalhos se debruça sobre as fronteiras que fazem parte do Arco Sul, ou seja, nas fronteiras com Argentina, Uruguai e Paraguai, território onde teve início o Programa Escolas (Bilíngues) Interculturais de Fronteira (PEIF), no ano de 2005, uma iniciativa dos Ministérios de Educação do Brasil e da Argentina como parte de ações da integração transnacional do Mercosul.

Porém, ainda existe uma carência no que diz respeito ao desenvolvimento de pesquisas em Política Linguística nas demais fronteiras do país, em especial naquelas que se localizam no Arco Norte, nos territórios amazônicos que atravessam Brasil, Peru, Colômbia e Venezuela, por exemplo.

Desta forma, o presente estudo, que faz parte da pesquisa de doutorado intitulada "Práticas e Políticas Linguísticas na Tríplice Fronteira do Alto Solimões: Multilinguismo e Desenvolvimento Sustentável", busca contribuir com as discussões sobre as particularidades e singularidades que formam esse trecho de fronteira entre Brasil e Colômbia formados pelas cidades de Tabatinga e Leticia, respectivamente, no que diz respeito à paisagem linguística dessa fronteira conurbada.

No imaginário popular, ao cruzar a fronteira de um país, automaticamente também se cruza a fronteira entre as línguas. Porém, na prática, os limites territoriais políticos entre duas ou mais nações não coincidem exatamente com seus limites linguísticos. Assim, Berger (2015, p. 46) propõe o termo "territórios linguísticos" para tratar de

[...] esferas de uso das línguas, não somente as demarcadas pelo poder exercido via instrumentos legais ou por intermédio de instâncias governamentais, mas também por outros agentes e grupos que, no campo das relações, agem sobre os usos das línguas, demarcando espaços de controle e fronteiras relacionais entre os grupos que delas compartilham, de forma descontínua.

Ou seja, a fronteira entre as línguas é descontínua e não pode ser estabelecida pelos mesmos critérios utilizados para a demarcação dos Estados, pois atuam, nesse espaço, outros fatores de ordens histórica, social, cultural, demográfica e econômica, que constituem esses territórios linguísticos de fronteira.

A paisagem linguística na fronteira, conforme apresento mais adiante, reflete essas "esferas de uso das línguas", as possíveis interações estabelecidas pelos habitantes desse espaço e a relação com as línguas que fazem parte desse território linguístico, como é o caso do português, do espanhol e das diversas línguas indígenas no Alto Solimões, como a língua ticuna.

Os Ticuna são o principal povo indígena que habita o Alto Solimões, estando distribuídos entre Brasil, Peru e Colômbia. No Brasil, suas comunidades estão localizadas nos municípios de Benjamin Constant, Tabatinga, São Paulo de Olivença, Santo Antônio do Içá, Amaturá, Jutaí, Fonte Boa, Beruri e Tonantins, no estado do Amazonas. Entre os Ticuna vivem indígenas de outras etnias, como os Kokama, os Kaixana e os Kanamari, sendo que os dois primeiros já não usam suas línguas maternas, mas o português e a língua ticuna; e o último, em menor número entre os Ticuna, ainda utiliza sua língua materna, a língua Kanamari².

Porém, neste primeiro estudo, não encontrei traços da presença dessas etnias e suas línguas na paisagem fronteiriça, revelando que a hegemonia é das línguas oficiais dos países

${ }^{2} \mathrm{D}$ ados do Instituto Socioambiental (ISA). Disponível em: <https://pib.socioambiental.org/pt/Povo:Ticuna> Acesso em: 15 maio 2019.

Revista Trama | Volume 16 | Número 37 | Ano 2020 | p. 149-160 | e-ISSN 1981-4674 


\section{$=$ TRAMA $=$}

onde esses grupos vivem, inclusive no sistema escolar, que não possibilita o estudo das línguas indígenas que são faladas nesse território.

Atualmente, as escolas de Tabatinga ofertam o espanhol como língua estrangeira e, de acordo com conversas informais com a gestão dessas escolas, muitos estudantes são de origem peruana, colombiana e indígena que se dirigem a essas instituições para aprender a língua portuguesa, revelando outra questão importante no que concerne à gestão das línguas nesse contexto, a aprendizagem do português em situação de contato.

Pensando nos contextos multilíngues das comunidades fronteiriças, neste artigo, proponho algumas discussões sobre a relevância da Paisagem Linguística para entender, analisar e propor políticas de gestão sobre as línguas nesses espaços onde a diversidade é uma realidade pulsante, visto que esses estudos vêm contribuindo para a compreensão das dinâmicas dos espaços multilíngues, para o desenvolvimento de políticas e para a gestão das línguas em contextos urbanos e, também, nos territórios fronteiriços.

A Paisagem Linguística (doravante PL) começa a germinar no final dos anos $1990 \mathrm{com}$ estudos de Landry e Bouhris (1997), ganhando novas perspectivas com Blommaert (2012), Shohamy (2006), Gorter e Cenoz (2008), Otsuji e Pennycook (2010), incorporando teorias como a superdiversidade (VERTOVEC, 2007) e da diversidade complexa (SCHILLER; CAGLAR, 2013).

Partindo desses conceitos e da premissa da importante contribuição da PL para os estudos sobre o multilinguismo em contexto fronteiriço, inicialmente, apresento algumas considerações sobre os conceitos de paisagem linguística, superdiversidade e metrolinguismo. Na seção seguinte, comento brevemente sobre a metodologia utilizada, para, por fim, propor uma análise da PL na fronteira seca entre Brasil e Colômbia, representadas, respectivamente, pelas cidades de Tabatinga e Leticia.

\section{PAISAGEM LINGUÍSTICA, SUPERDIVERSIDADE E METROLINGUISMO}

A paisagem urbana de um território pode revelar os processos de interação humana que resultam na modificação dessa paisagem baseada em critérios de ordens cultural, social e econômica. Nesse sentido, a língua é parte importante na transformação da paisagem de um território, constituindo o que autores como Landry e Bouhris (1997) denominam de paisagem linguística e que, atualmente, é um dos temas estudados sob a ótica da Política Linguística.

Blommaert (2012, p. 4-5) define a PL como "um ramo da sociolinguística que poderia ser de imenso valor interdisciplinar. A razão é a clara sobreposição entre LLS [linguistic landscape] e disciplinas como geografia social, estudos urbanos e a antropologia e sociologia da diversidade". ${ }^{3}$ Ou seja, os estudos sobre a paisagem linguística possuem um caráter nitidamente interdisciplinar, que permitem analisar e conhecer determinado território e sua comunidade a partir de como estão desenhados e dispostos os diversos sinais linguísticos em sua paisagem.

Desta forma, a paisagem linguística pode ser compreendida como um conjunto de signos linguísticos disponíveis nas vias públicas de uma determinada área, abrangendo nomes de ruas, placas, nomes de instituições públicas e privadas, que contêm informações linguísticas direcionadas aos falantes que fazem parte desse território, cujas construções sociais, históricas

\footnotetext{
${ }^{3}$ Original: "I see LLS as one branch of sociolinguistics that could be of immense interdisciplinary value. The reason is the clear overlap between LLS and disciplines such as social geography, urban studies and the anthropology and sociology of diversity" (BLOMMAERT, 2012, p. 4-5).

Revista Trama | Volume 16 | Número 37 | Ano 2020 | p. 149-160 | e-ISSN 1981-4674
} 


\section{$=$ TRAMA $=$}

e políticas podem ser detectadas através dessa paisagem e fazer parte das políticas linguísticas dessa comunidade.

Essa paisagem se modifica à medida em que ocorrem transformações de diversos níveis e intensifica-se com os movimentos migratórios e a presença de múltiplas culturas e línguas nos territórios. Nesse sentido, o multilinguismo e o multiculturalismo são uma constante na sociedade. Os novos grupos sociais se inserem paulatinamente nos territórios, inclusive em sua paisagem linguística, como é possível observar no estudo etnográfico desenvolvido por Lombardi, Salgado e Soares (2016) sobre a paisagem social e linguística da cidade de Juiz de Fora e a superdiversidade no que concerne aos contatos linguísticos e culturais observados em placas de lojas, pichações e nomes de prédios em diversos bairros da cidade.

Através da paisagem, é possível verificar a presença da superdiversidade, ao observar como as línguas se inserem nos diversos espaços públicos e privados de um determinado território, revelando as relações estabelecidas entre os sujeitos que coabitam esse espaço.

Neste sentido, contribui para os estudos sobre a PL a concepção de metrolinguismo, que

[...] descreve as maneiras pelas quais pessoas de origens diferentes e mistas usam, brincam e negociam identidades através da linguagem; não assume conexões entre língua, cultura, etnia, nacionalidade ou geografia, mas procura explorar como tais relações são produzidas, resistidas, desafiadas ou rearranjadas; seu foco não está nos sistemas de linguagem, mas nas linguagens emergentes de contextos de interação (OTSUJl; PENNYCOOK, 2009, p. 246) ${ }^{4}$.

De acordo com o conceito de metrolinguismo, não bastam as diferentes línguas e culturas, mas como os sujeitos constroem e reconstroem identidades e novas linguagens em situações diversas de contato, conflitos e busca por soluções. Desse modo, não importa apenas o código linguístico, mas as relações sociais, as ideologias e práticas linguísticas que se estabelecem nesses contextos superdiversos.

Neste sentido, devido à presença e ao fluxo de pessoas de diversas culturas, línguas e etnias, o território fronteiriço é um espaço superdiverso por natureza, onde esses sujeitos estabelecem relações de interação com outros sujeitos, desenvolvendo práticas sociais e linguísticas que refletem suas ideologias e crenças, como é possível observar na fronteira seca entre Brasil e Colômbia, respectivamente representada pelas cidades de Tabatinga e Leticia, que conforma a tríplice fronteira do Alto Solimões, ao incluir-se a ilha fluvial de Santa Rosa, no território peruano.

\section{CAMINHOS METODOLÓGICOS}

Como o título do artigo indica, optei pelo estudo de caso como abordagem metodológica para a análise da paisagem linguística, por compreender que esse enfoque

[...] permite uma investigação para se preservar as características holísticas e significativas dos eventos da vida real - tais como ciclos de vida individuais, processos organizacionais e administrativos, mudanças ocorridas em regiões urbanas, relações internacionais e a maturação de alguns setores (YIN, 2001, p. 21).

\footnotetext{
${ }^{4}$ Original: "Metrolingualism describes the ways in which people of different and mixed backgrounds use, play with and negotiate identities through language; it does not assume connections between language, culture, ethnicity, nationality or geography, but rather seeks to explore how such relations are produced, resisted, defied or rearranged; its focus is not on language systems but on languages as emergent from contexts of interaction". (OTSUJI; PENNYCOOK, 2009, p. 246).
}

Revista Trama | Volume 16 | Número 37 | Ano 2020 | p. 149-160 | e-ISSN 1981-4674 


\section{$=$ TRAMA $=$}

Assim, como abordagem qualitativa, o estudo de caso permite conhecer determinada situação social real a fim de interpretá-la a partir dos dados gerados, com o subsídio de variados instrumentos e fontes, como as fotografias aqui utilizadas, como instrumentos de análise.

A própria PL pode ser considerada um instrumento muito relevante para a elaboração de diagnósticos sociolinguísticos em comunidades multilíngues, como aquelas que se estendem ao longo das fronteiras, auxiliando no conhecimento de seus repertórios comunicativos e as acepções sobre o espaço e papel dessas línguas nesses grupos socais.

Desta forma, o estudo de caso que apresento tem como objeto de estudo a paisagem linguística da fronteira entre Brasil e Colômbia, a partir da análise de fotografias de placas de estabelecimentos comerciais, pichações e placas encontradas nas imediações do marco de fronteira, registradas durante a pesquisa de campo realizada no mês de maio de 2019, entre as cidades de Tabatinga e Leticia, as quais se ligam através das avenidas da Amizade e Internacional, respectivamente.

\section{A PL NA FRONTEIRA BRASIL-COLÔMBIA: UM OLHAR SOBRE TABATINGA E LETICIA}

Antes de tratar especificamente sobre a PL, considero importante comentar brevemente sobre o contexto histórico que sustenta a atual configuração da fronteira entre Brasil, Peru e Colômbia. Esses territórios foram alvo de grandes disputas durante os períodos colonial, de pós-independência e da construção dos atuais Estados-Nação que passaram a controlar esse território, como indicam o surgimento da cidade de Tabatinga e as disputas entre peruanos e colombianos pelo território que hoje é Leticia.

A cidade de Tabatinga surge inicialmente como uma aldeia jesuíta em meados do século XVII. No ano de 1766, foi transformada em um posto militar e, nas imediações do forte, constituiu-se o povoado de São Francisco Xavier de Tabatinga, conferindo-lhe um caráter de território militarizado, que perdura até os dias atuais com a presença do Comando de Fronteira Solimões e do $8^{\circ}$ Batalhão de Infantaria de Selva.

Após ser transformada em colônia militar em 1967, Tabatinga vai ser elevada à categoria de município apenas em 1983 com a Emenda Constitucional do Estado do Amazonas, vinte anos após a criação do município de Leticia, no território colombiano, elevado a essa categoria em 1963, mesmo já sendo capital da Comisaría del Amazonas desde 1930.

Leticia, por sua vez, surge após cem anos da instalação do Forte de São Francisco Xavier de Tabatinga, como parte do território peruano em constante disputa com a Colômbia (STEIMAN, 2002). Atualmente, conforma um centro de compras para brasileiros e peruanos, fornecendo mercadorias para a ilha fluvial de Santa Rosa, no Peru.

Tabatinga e Leticia recebem um grande fluxo de indígenas oriundos das comunidades próximas, que se deslocam a essas cidades para ter acesso a serviços bancários, entre outros, e continuar os estudos em escolas não-indígenas do município; assim como estudantes peruanos que vêm continuar seus estudos nas escolas do Brasil ou da Colômbia.

Tais considerações revelam a diversidade complexa que permeia o contexto fronteiriço. Pensando nos termos de Schiller e Caglar (2013 apud CRUL, 2016, p. 58),

[...] não podemos abordar pessoas da mesma origem nacional ou étnica de migrantes de maneira homogênea em termos de seus valores, repertório cultural, oportunidades de habilidades ou identidade. Essa realidade exige uma nova perspectiva teórica que ilumine mais a interação dinâmica entre etnia, geração, faixa etária, educação, gênero e status legal, por um lado, e o contexto de integração maioria-minoria nas grandes cidades, por outro. 


\section{$=$ TRAMA $=$}

Nesse sentido, a teoria da diversidade complexa, aliada ao estudo da PL, pode ser de grande relevância para o desenvolvimento de políticas linguísticas em prol do multilinguismo e da utilização das línguas como recurso de integração entre os países, uma vez que

A paisagem linguística pode fornecer informações sobre o contexto sociolinguístico e o uso das diferentes linguagens nos signos da linguagem pode ser comparado à política oficial da região e ao uso da linguagem conforme relatado nas pesquisas. O estudo da paisagem linguística também pode ser interessante porque pode fornecer informações sobre as diferenças entre a política oficial de idioma que podem ser refletidas nos sinais de topo como nomes de ruas ou nomes de edifícios oficiais e o impacto dessa política sobre os indivíduos como refletido em sinais de baixo para cima, como nomes de lojas ou cartazes de rua (CENOZ; GORTER, 2006, p. 68, tradução minha) ${ }^{5}$.

Desta forma, através da análise da paisagem linguística, é possível conhecer as dinâmicas de uso das línguas no território fronteiriço e os recursos comunicativos forjados nos processos interativos entre os sujeitos que transitam nesse espaço, além do poder simbólico das línguas nesse contexto superdiverso, conforme podemos observar nas figuras que seguem.

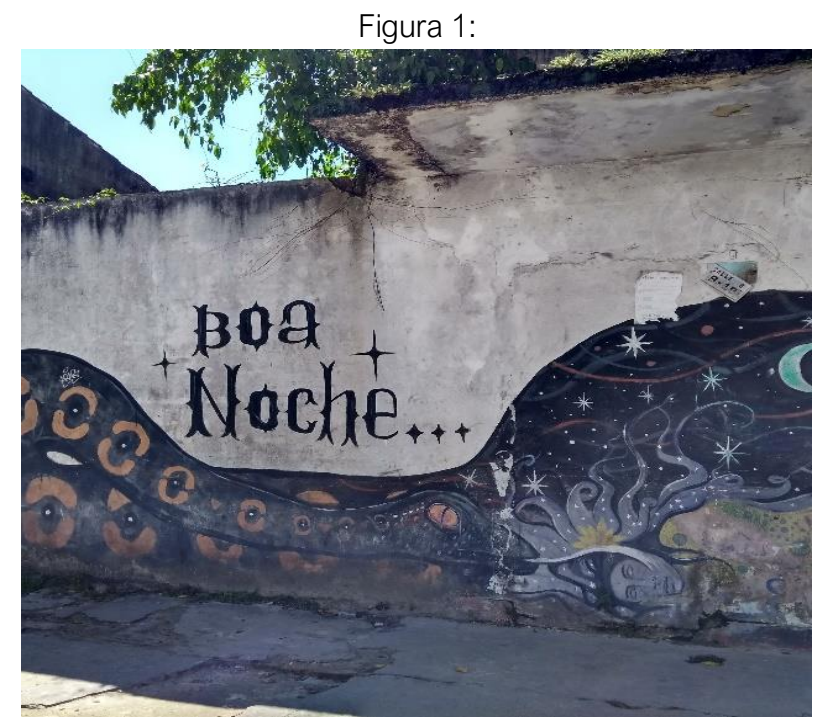

Fonte: Trabalho de campo, fotografia por Luana Rodrigues (2019).

A primeira fotografia foi coletada no centro da cidade de Leticia, Colômbia, e retrata uma pichação no muro de um terreno abandonado com o cumprimento "boa noche". Essa rua tem bastante movimento, pois, nela, localiza-se parte do comércio da cidade, bastante frequentado por colombianos, brasileiros residentes em Tabatinga e Benjamin Constant e peruanos oriundos de Santa Rosa e Islândia. A grafia reflete a linguagem oral, chamada por residentes na região de "portunhol leticiano", que consiste em uma interlíngua entre o português e o espanhol.

Figura 2:

\footnotetext{
${ }^{5}$ Original: The linguistic landscape can provide information about the sociolinguistic context and the use of the different languages in language signs can be compared to the official policy of the region and to the use of the language as reported in surveys. The study of the linguistic landscape can also be interesting because it can provide information on the differences between the official language policy that can be reflected in topdown signs such as street names or names of official buildings and the impact of that policy on individuals as reflected in bottom-up signs such as shop names or street posters. (CENOZ; GORTER, 2006, p. 68) Revista Trama | Volume 16 | Número 37 | Ano 2020 | p. 149-160 | e-ISSN 1981-4674
} 


\section{$=\mathrm{T} R A M A=$}

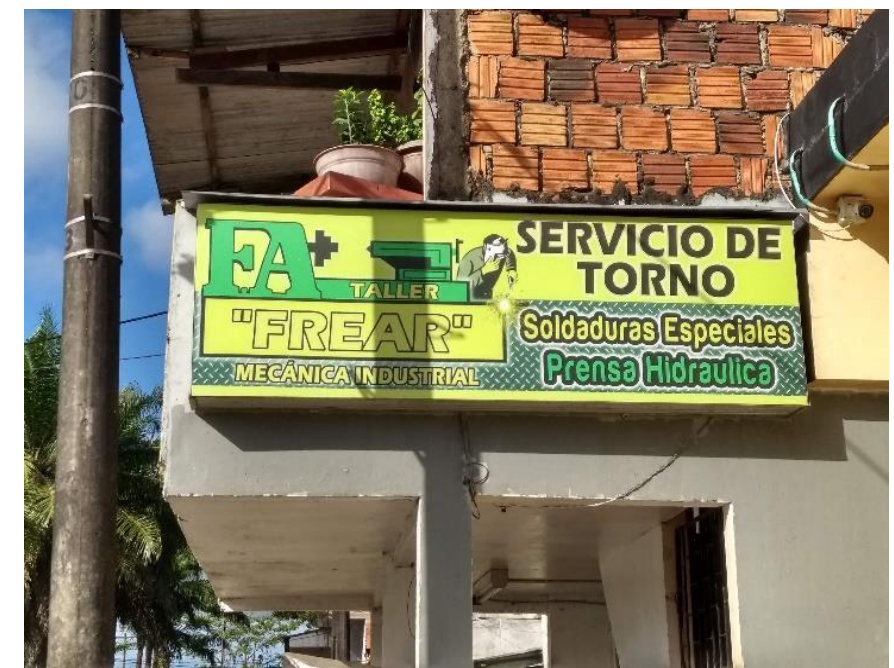

Fonte: Trabalho de campo, fotografia por Luana Rodrigues (2019).

$\mathrm{Na}$ segunda figura, temos a fotografia da fachada de um estabelecimento comercial, uma oficina, localizada próximo ao marco da fronteira, já em território colombiano, que utiliza o termo frear entre aspas, sinalizando que é uma palavra estrangeira. Nesse caso, ocorre a utilização de uma palavra do português substituindo o "frenar" do espanhol, sinalizando que aquele estabelecimento provavelmente tem um fluxo de clientes brasileiros.

Figura 3:

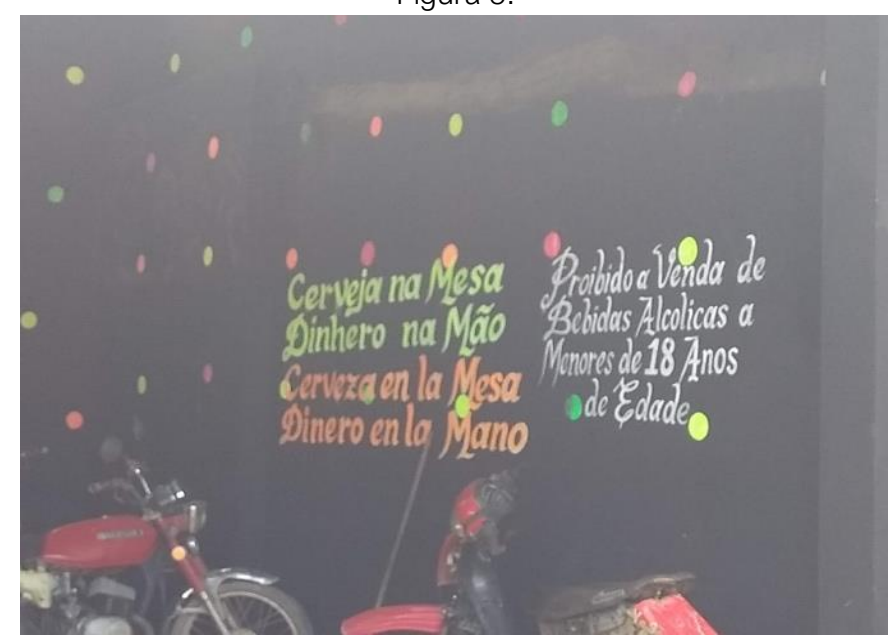

Fonte: Trabalho de campo, fotografia por Luana Rodrigues (2019).

$\mathrm{Na}$ terceira fotografia, tomada em um bar na cidade de Tabatinga, em uma zona de bares, restaurantes, bancos e escolas, na Avenida da Amizade, vemos algumas regras do estabelecimento escritas em português com a tradução logo abaixo na primeira coluna. $\mathrm{Na}$ segunda coluna, há a utilização da palavra "edade" do espanhol em lugar de "idade" e a grafia da palavra "alcolicas" que também pode ser uma influência da escrita de "alcoholica" do espanhol ou apenas um equívoco na grafia em português. 


\section{$=$ TRAMA $=$}

Figura 4

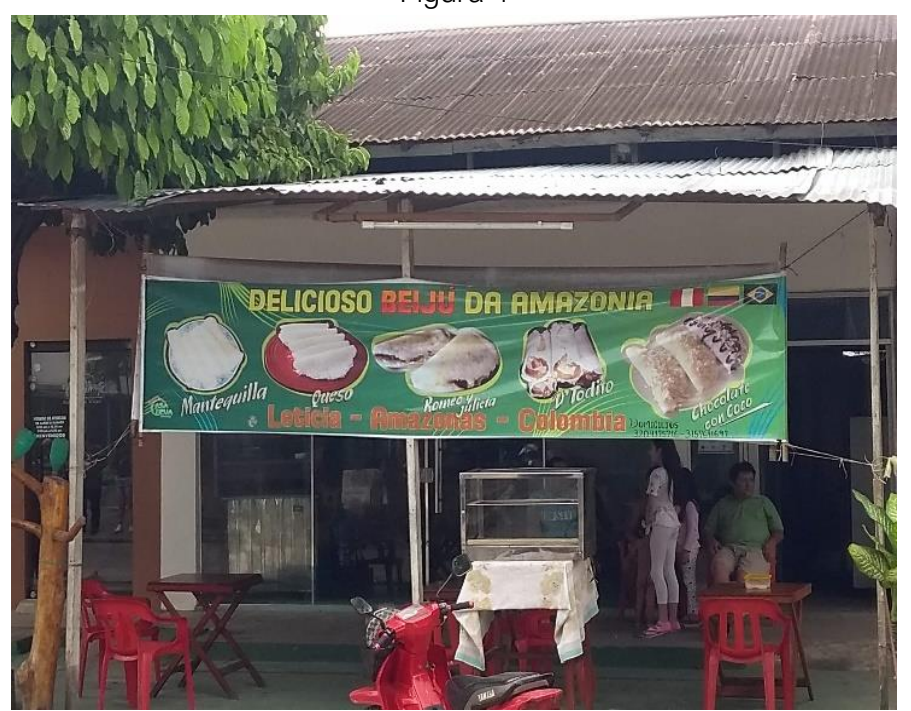

Fonte: Trabalho de campo, fotografia por Luana Rodrigues (2019).

$\mathrm{Na}$ figura 4, temos um estabelecimento comercial, em Leticia, que utiliza a descrição do produto em língua portuguesa, "delicioso beiju da Amazonia", porém as opções de recheio para o acepipe são oferecidas em espanhol. Chama a atenção também a utilização do termo "beiju", mais difundido entre falantes de português na região nordeste do Brasil, uma vez que, na região norte, a mesma iguaria é denominada de "tapioca".

Figura 5:

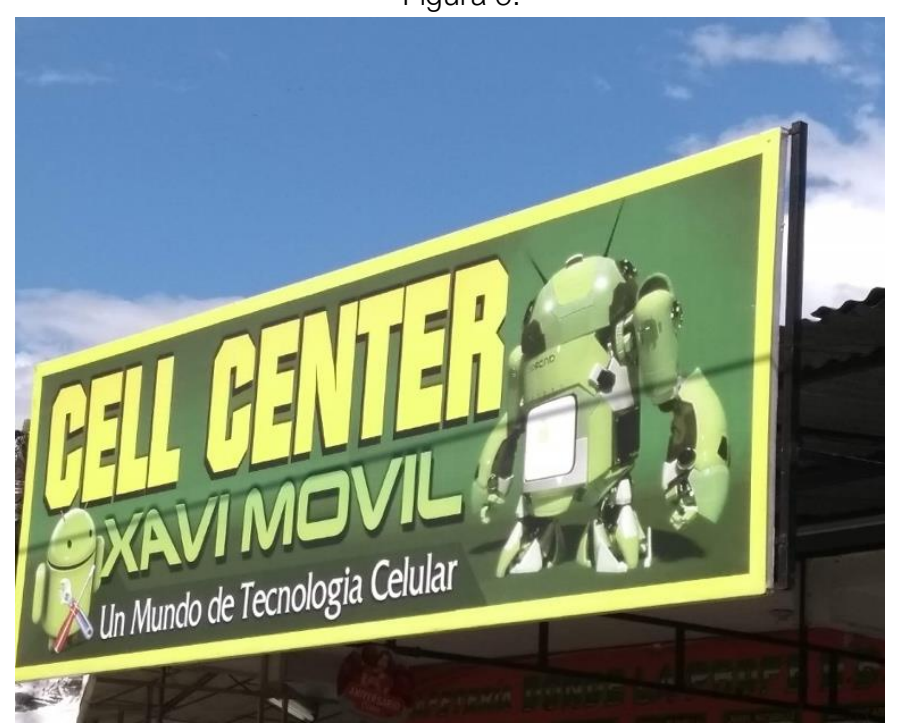

Fonte: Trabalho de campo, fotografia por Luana Rodrigues (2019). 


\section{$=$ TRAMA $=$}

Figura 6:

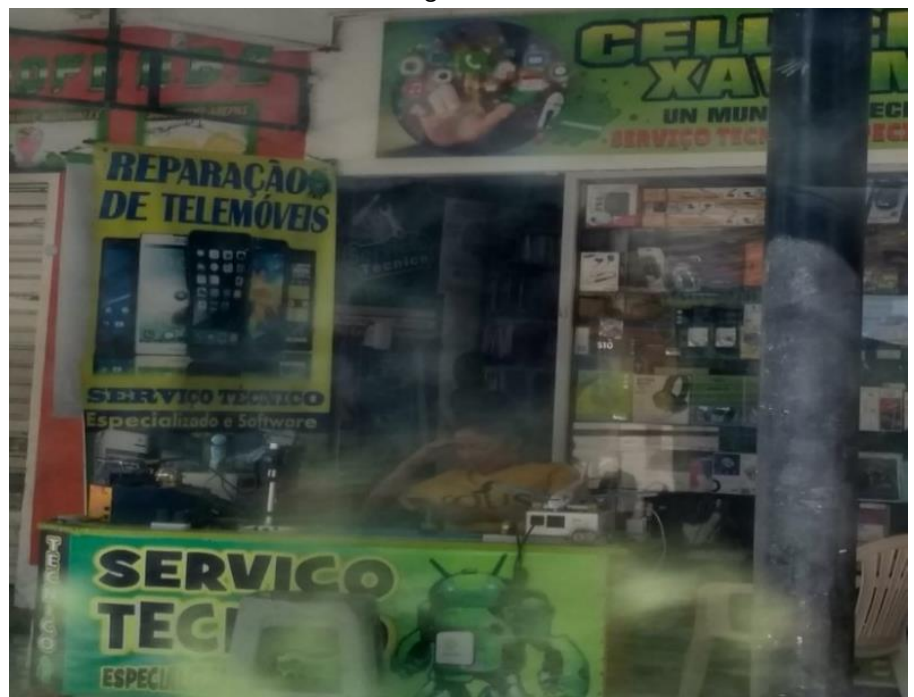

Fonte: Trabalho de campo, fotografia por Luana Rodrigues (2019).

As figuras 5 e 6 são do mesmo estabelecimento, localizado na cidade de Leticia, nas quais é possível perceber a utilização de três línguas: o inglês, o espanhol e o português. Como é comum em lojas de eletrônicos ou telefonia celular, na figura 5, vemos que este comércio leva o nome fantasia em língua inglesa, "Cell Center", porém com o subtítulo em espanhol "Xavi Movil: un mundo de tecnologia celular".

Na figura 6, vemos uma placa localizada na entrada da loja com uma descrição em português dos serviços oferecidos: "reparação de telemóveis, serviço técnico especializado e software". Nesta imagem, é possível inferir que a loja atende brasileiros que vão em busca de consertos de celulares na cidade colombiana e que talvez a inscrição na placa seja resultado de uma tradução automática, visto que utilizam a palavra "telemóveis", mais utilizada em Portugal e em outros países lusófonos para a palavra "celular", amplamente utilizada no Brasil.

Além desses elementos presentes na paisagem das duas cidades, cabe comentar sobre a forte influência musical colombiana e peruana no lado brasileiro, uma vez que é comum escutar ritmos desses países nos estabelecimentos de Tabatinga. O mesmo ocorre em relação aos estabelecimentos em Leticia, onde é comum ouvir músicas brasileiras, normalmente sertanejo ou outros ritmos mais populares.

A paisagem linguística da fronteira entre Brasil e Colômbia revela a presença de políticas linguísticas bottom-up praticadas por pessoas que pertencem ao âmbito privado, diferente das políticas top-down que são colocadas em prática pelo poder público ${ }^{6}$. Não foram observadas, em ambas cidades, políticas top-down, ou seja, placas de ruas, placas turísticas, nomes de ruas ou outras manifestações escritas oriundas de ações governamentais que refletissem a realidade multilíngue dessas comunidades.

É possível observar o poder simbólico das línguas na paisagem linguística da fronteira entre Brasil e Colômbia, ao invocarmos Bourdieu (1989, p. 11), quem afirma que "as relações de comunicação são, de modo inseparável, sempre, relações de poder que dependem, na forma e no conteúdo, do poder material e simbólico acumulados pelos agentes".

Desta forma, a presença do português e do espanhol na paisagem linguística da fronteira, em contraste com a ausência de referências nas línguas autóctones, que são parte

\footnotetext{
${ }^{6}$ Sobre as políticas bottom-up e top-down nos espaços públicos ver Spolsky (2009). Revista Trama | Volume 16 | Número 37 | Ano 2020 | p. 149-160 | e-ISSN 1981-4674
} 


\section{$=$ TRAMA $=$}

da construção histórica, social e identitária dessas comunidades, revela o jogo de forças entre as duas línguas oficiais nos Estados-Nação. As relações se constroem ao redor da comunicação em uma língua ou outra na fronteira, sem que haja uma preocupação com a inserção e promoção das línguas indígenas dos diversos grupos étnicos que transitam ou habitam esse espaço.

Neste sentido, podemos detectar as funções propostas por Landry e Bouhris (1997 apud BERGER; LECHETA, 2019, p. 5) para a PL. Primeiramente, a função simbólica representada pelo poder hegemônico das línguas oficiais explícito não apenas na paisagem linguística, mas também no sistema educativo dos municípios, onde não há qualquer menção ou implementação de políticas que visem à promoção das línguas indígenas nas escolas estaduais não-indígenas que aponta, portanto para uma invisibilização dessas línguas. Em segundo, a função informativa refletida nas escolhas linguísticas dos agentes não-oficiais (comerciantes, nos exemplos aqui expostos) que funcionam como delimitadoras do território na zona fronteiriça.

Outro ponto que merece reflexão no estudo da $P L$ da fronteira é a ruptura com a crença de que as línguas são circunscritas a um território, como se, ao cruzar a fronteira, a língua ficasse estacionada do outro lado do marco fronteiriço, que, em muitos casos, é apenas uma rua, e a língua do outro país pudesse entrar em ação ao fazer a travessia.

Nas figuras aqui analisadas, é possivel perceber que as línguas estão permanentemente em contato, em um jogo de conflitos que seus falantes buscam resolver com a utilização de recursos que permitam a comunicação, como a utilização do "portunhol leticiano" nas zonas comerciais de Leticia, revelando a criatividade do falante em buscar soluções para os conflitos linguísticos que emergem nas situações de contato.

Por último, é possível verificar o quanto o estudo da PL de um determinado espaço permite compreender as relações que se estabelecem entre as línguas e seus falantes e o status que essas línguas adquirem nesses processos interativos, possibilitando uma ampliação da percepção sobre as línguas nas pesquisas que se desenvolvem sob a ótica da Política Linguística.

\section{CONSIDERAÇÕES FINAIS}

O estudo sobre a paisagem linguística de uma comunidade pode ser um grande aliado no estabelecimento de políticas que visem a dar visibilidade à diversidade das línguas e culturas presentes em seu território, consequentemente como um recurso para a promoção do multilinguismo.

Ao pensar essa paisagem em contexto fronteiriço desde o imaginário popular, muitas vezes se pensa na existência de uma divisão entre onde se fala uma língua e onde a outra começa, porém, é perceptível que, na realidade, esses territórios linguísticos são construídos por seus falantes de acordo com fatores que não coincidem com os pressupostos políticos de demarcação das fronteiras.

O estudo de caso aqui proposto teve como objetivo trazer uma breve apresentação da paisagem linguística da fronteira entre Brasil e Colômbia, que compreendem, respectivamente, as cidades de Tabatinga e Leticia, discutindo conceitos que giram em torno da superdiversidade, do metrolinguismo e do poder simbólico das línguas hegemônicas nesse espaço, apesar da soberana riqueza linguística que caracteriza os territórios amazônicos e que vem tentando resistir às inúmeras tentativas de extermínio de seus povos ao longo dos séculos e ainda nos dias atuais. 


\section{$=\mathrm{T} R A M A=$}

Esse poder das línguas hegemônicas pode ser visto por meio da ausência de uma representação das demais línguas e identidades que fazem parte da construção social e cultural desse território fronteiriço; também pode ser visto no sistema educativo dos municípios envolvidos, uma vez que não existe legislação estadual ou municipal que regulamente a oferta de línguas autóctones nas escolas nos municípios dos dois países.

Por fim, é possível verificar a ausência de políticas top-down sobre a paisagem das cidades do estudo, revelando a necessidade de se pensar uma gestão do multilinguismo por parte do poder público, que planeje e implemente a inserção das línguas da comunidade nessa paisagem. Ben-Rafael et al. (2006, p. 10) vão denomina-la "construção simbólica do espaço público", uma vez que a PL de um território vai além de placas, letreiros ou nomes de prédios públicos e privados: ela é o reflexo dos sujeitos que habitam e desenham, nesse território, os traços que forjam suas identidades superdiversas e complexas.

E, por último, é importante frisar a necessidade de se pensar uma educação linguística que promova a representatividade social, identitária e linguística dos sujeitos que habitam essas comunidades através da inserção das suas línguas no currículo escolar, oferecendo a todas a possibilidade de ver sua língua como um recurso para a integração transnacional em um espaço onde vários rios convergem para formar as diversas identidades amazônicas.

\section{REFERÊNCIAS}

BEN-RAFAEL, E.; SHOHAMY, E.; AMARA, M. H.; TRUMPER-HECHT, N. Linguistic Landscape as Symbolic Construction of the Public Space: The Case of Israel. In: GORTER, D. Linguistic Landscape: New Approach to Multilingualism. Clevedon: Multilingual Matters Ltd., 2006. p. 7-30.

BERGER, I. R. Gestão do .multi/plurilinguismo em escolas brasileiras na fronteira Brasil - Paraguai: um olhar a partir do Observatório da Educação na Fronteira. 2015. Tese (Doutorado em Linguística) - Centro de Comunicação e Expressão, Universidade Federal de Santa Catarina, Florianópolis, 2015. Disponível em: < https://repositorio.ufsc.br/handle/123456789/133000> Acesso em: 14 jun. 2018.

BERGER, I. R.; LECHETA, M. A paisagem linguística de um campus universitário fronteiriço: língua e poder em perspectiva. Entrepalavras, Fortaleza, v. 9, n. 2, p. 01-19, 2019.

BLOMMAERT, J. Chronicles of complexity Ethnography, superdiversity, and linguistic landscapes. Tilburg: Tilburg Papers in Culture Studies, 2012.

BLOMMAERT, J.; RAMPTON, B. Language and Superdiversity. MMG Working Paper Print. Göttingen, 2012. BOURDIEU, P. O poder simbólico. Rio de Janeiro: Bertrand Brasil, 1989.

CENOZ, J.; GORTER, D. El estudio del paisage lingüístico. Amsterdam: Journal Hizkunea, 2008. P.1-10.

Disponivel em: <https://hdl.handle.net/11245/1.293687> Acesso em: 04 abr. 2019.

CENOZ, J; GORTER, D. Linguistic Landscape and Minority Languages. International Journal of Multilingualism, Vol. 3, No. 1, 2006. Disponível em: <

http://citeseerx.ist.psu.edu/viewdoc/download?doi=10.1.1.573.7767\&rep=rep1\&type=pdf $>$ Acesso em 15 jul. 2019.

CRUL, M. Super-diversity vs. assimilation: how complex diversity in majority-minority cities challenges the assumptions of assimilation. Journal of Ethnic and Migration Studies, 42:1, p. 54-68, 2016. Disponível em: < https://doi.org/10.1080/1369183X.2015.1061425> Acesso em 14 ago. 2019.

LANDRY, R.; BOURHIS, R. Y. Linguistic Landscape and Ethnolinguistic Vitality: An Empirical Study. Journal of Language and Social Psycology, Mar., v. 16, n. 1, p. 23-49, 1997. Disponível em: https://doi.org/

10.1177/0261927X970161002 Acesso em 14 ago. 2019.

LOMBARDI, R. S.; SALGADO, A. C. P.; SOARES, M. S. Paisagem linguística e repertórios em tempos de diversidade: uma situação em perspectiva. Calidoscópio, v. 14, n. 2, p. 209-218, maio/ago., 2016. Disponível em: < http://revistas.unisinos.br/index.php/calidoscopio/article/viewFile/cld.2016.142.03/5558> Acesso em 08 ago. 2019

OTSUJI. E.; PENNYCOOK, A. Metrolingualism: fixity, fluidity and language in flux. International Journal in Multilingualism, 7:3, p. 240-254, 2009. Disponível em: < http://dx.doi.org/10.1080/14790710903414331> Acesso em 25 jul. 2019.

SCHILLER, N. G., ; CAGLAR, A. Locating Migrant Pathways of Economic Emplacement: Thinking Beyond the Ethnic Lens." Ethnicities 13 (4): 494-514 , 2013. Disponível em: <

https://www.researchgate.net/publication/258136583_Locating_Migrant_Pathways_of_Economic_Emplaceme nt_Thinking_Beyond_the_Ethnic_Lens> Acesso em 12 ago. 2019. 
SHOHAMY, E. Language Policy: hidden agendas and new approaches. Nova York: Routledge, 2006. Disponível em: < https://doi.org/10.4324/9780203387962 > Acesso em 23 ago. 2019.

SPOLSKY, B. Prolegomena to a Sociolinguistic Theory of Public Signage. In: GORTER, D.; SHOHAMY, E. Linguistic Landscape: Expanding the scenary. Nova York: Routledge, 2009. p.25-39.

STEIMAN, R. A geografia das cidades de fronteira: um estudo de caso de Tabatinga (Brasil) e Letícia (Colômbia). 2002. Dissertação de Mestrado em Geografia, Universidade Federal do Rio de Janeiro, Rio de Janeiro, 2002. Disponível em: < http://objdig.ufrj.br/16/teses/581220.pdf> Acesso em 05 mar. 2018.

VERTOVEC, S. Super-diversity and its implications. Ethnic and Racial Studies, v. 30, n. 6, p. 1024-1054, 2007. Disponível em: <http://www.informaworld.com/smpp/title content=t713685087>. Acesso em: 06 jun. 2019.

YIN, R. K. Estudo de caso: planejamento e métodos. 2. ed. Porto Alegre: Bookman, 2001.

Recebido em 29-11-2019.

Aceito em 10-02-2020. 